\title{
Analysis of the Reliability of Information Services as Part of Management Systems of Complex Technical Objects
}

\author{
Vladimir Gvozdev \\ Ufa State Aviation Technical \\ University \\ Ufa, Russia \\ wega55@mail.ru
}

\author{
Liliya Chernyahovskaya \\ Ufa State Aviation Technical \\ University \\ Ufa, Russia \\ lrchern@yandex.ru
}

\author{
Rima Nasyrova \\ Ufa State Aviation Technical \\ University \\ Ufa, Russia \\ nasyrova.rima@yandex.ru
}

\begin{abstract}
To achieve the objectives of Industry 4.0 doctrine, it is necessary to create "smart factoring". Building information service profiles plays a supporting role in making decisions on priority areas for the development of information systems as part of "smart factoring". This article analyzes the current state of research into the field of functional security management of hardware and software complex. The article also proposed an approach based on the concept of service profiles, which allows you to look at the system through the eyes of the user and evaluate the reliability of the service using fuzzy logic. In this case, the evaluation of reliability characteristics is carried out on the basis of a comparison of the conformity of service properties to functional and non-functional requirements for software products. At the end of the article, the limitations of the proposed approach and possible ways of removing these limitations are described.
\end{abstract}

Keywords-Industry 4.0, information systems reliability, service, profile, functional security.

\section{INTRODUCTION}

Currently in the literature there is a stormy discussion of the content, strategies for achieving the global goals of Industry 4.0 doctrine, its position on the doctrine of Society 5.0 [1-3], etc. At the same time, in all literary sources there is no doubt about the need to create smart productions ("smart factoring"), the basis of which is ensuring sustainable development at industrial enterprises of the digital ecosystem.

The basic position of Industry 4.0 doctrine is the formation of a digital ecological environment, the platform for which are distributed dynamic systems for receiving, collecting, systematizing, processing, storing data, accessing data, information and knowledge. Thus, the problem of reliable and effective functioning of such systems becomes urgent. Currently, much attention is paid to the tasks of information security related to countering external attacks on information systems. On the contrary, due attention is not paid to the tasks of functional safety focused on the management of non-criminal defects [19]. It should be noted that the results of information system failures due to the presence of non-criminal defects in software products can cause more damage than the consequences of criminal defects caused by targeted attacks $[4,5]$.
The concept of "Information - computer system" (ICS) [6] emphasizes the indivisible unity of the processes of data transmission and processing. The reliability of the components of distributed ICS is determined by the reliability of both hardware and software components. But, firstly, the ability to affect the reliability of the hardware of the developers of the ICS is less than the reliability of the software, and secondly, the reliability of the hardware component of the ICS is now higher than the software [18]. Therefore, if we consider the component of distributed ICS as a whole, then it can be argued that the reliability of this component acceptable from the point of view of supporting the management of a complex system is determined by the reliability of the software.

Until now, in the literature on the reliability of software systems (SS), the approach focused on finding defects in software codes has been invariant to the environment in which this software will be used. But it is important that the consumer is interested in the reliability not of the program code, but of the service that is provided to him. In [7] an approach to the analysis of the reliability of SS, based on the use of the concept of profiles, is described. The basis of this approach is the maximum accounting at the initial stages of designing all the features of the use of SS in order to ensure that the reliability of services meets the requirements of users.

The implementation of the provisions of Industry 4.0 doctrine, compared with the doctrine focused on automation of production processes, implies the replacement of a function-oriented approach to building management information support systems with a process-oriented one. This means a shift in emphasis from the question "how to do" to the question "what to do so that the customer is satisfied." The change of methodologies for building information support systems as part of management systems for complex technical objects makes it possible to single out the management of information services reliability as an independent task of managing functional safety as an independent task [19].

This paper is devoted to a discussion of approaches to the analysis of the reliability of information services based on the concept of profiles. 


\section{ANALYSIS OF THE CURRENT STATE OF RESEARCH IN THE FIELD OF FUNCTIONAL SAFETY MANAGEMENT OF HARDWARE AND SOFTWARE SYSTEMS}

The qualitative increase in the role of data processing systems in the management of modern distributed technical systems highlights the problem of managing the functional safety of the hardware and software complex (HSC). From the analysis of literary sources [16, 26-28], it can be concluded that there are differences in approaches to the management of unintentionally admitted defects at different stages of the life cycle, including the pre-design stage, due to the difference in the factors causing the occurrence of defects. At the initial stages of the life cycle, defects prevail, due to the uncertainty of the environment of use and the ambiguity of management objectives. As we move from the initial stages of the life cycle to the final stages, the emphasis is shifted to the area of misuse of development guides, tools technology, violation of the areas of applicability of models. The methods used for defect management can be correlated with proactive, active and reactive approaches to the management of complex systems. At the same time, approaches that correlate with active and reactive approaches prevail, i.e. methods aimed at identifying errors according to the results of specially organized tests and studying historical data on the experience of the operation of the HSC in order to establish patterns in the manifestations of symptoms of defects, as well as the causes of defects [17, 26 - 28]. This group of methods, united by the concept of Root Couse Analysis, is an adaptation of the provisions of the ITRIZ methodology [28] to the area of functional safety management of the HSC, namely, methods belonging to the class Anticipatory Failure Determination - AFD-2. Another area that is being actively developed at the present time as part of an active approach to the management of functional safety of the HSC includes methods that can be combined by the concept of Error Propagation Analysis [29-32]. The essence of these methods consists in the early detection of manifestations of defects and failures and the countering of these phenomena.

The methods based on a proactive approach to managing complex systems include, firstly, methods focused on a comparative analysis of alternative design solutions based on functional safety criteria (Failure Mode and Effect Analysis - FMEA; Fault Tree Analysis - FTA) [12, 13, 33]. It is also necessary to single out a group of methods focused on the prevention of defects caused by errors of a subjective nature [23-25].

In the works $[9,10]$ it is emphasized that among the critical factors that negatively affect the success of the implementation of projects for the creation of the HSC, are the insufficient quality of the functional and non-functional requirements for consumer properties of the systems. This, in particular, is due to the complexity of forming a consolidated opinion of various target user groups in the context of uncertainty of the environment of use and the vagueness of the goals of complex systems [14, 34-36]. The work [34, 35] substantiates the need to develop approaches to the development of consolidated solutions based on convergent management methods and the development of network technologies for coordinating the decisions of various stakeholders. At the same time, in the mentioned works the emphasis is placed on the "useful functions" of the controlled systems. Outside the scope of research, "harmful functions" remain, including those caused by various kinds of errors and defects.

The results of a critical analysis of the possibilities of using approaches to the design of technical systems with embedded real-time HSC are presented in [2022]. It is noted that general-purpose software development tools are of limited use in the development of data processing and real-time control systems. In [22] it is noted that the existing tools for supporting parallel processes (semaphores; priorities, etc.) do not provide the necessary capabilities for reliable and predictable behavior of distributed technical systems with embedded software. It is noted that objects that successfully pass the verification do not guarantee stable and predictable behavior in the conditions of instability and uncertainty of the external environment. A special type of defects due to the violation of restrictions on the allowable data processing time is discussed (this type of defects is also mentioned in [19]). In the works [20-22] the conclusion is substantiated about the need to develop new approaches to the design of distributed HSC, taking into account the features of real-time control tasks. Extrapolating this conclusion, it can be argued that it is necessary to isolate new types of defects characteristic of distributed complex technical systems with real-time embedded software, and to study the methodological, theoretical and applied aspects of managing such defects.

The analysis of literature sources makes it possible to conclude that research is dominant, firstly, aimed at managing defects arising from the use of formalized and formal procedures for designing general purpose HSCs and having limited use in designing distributed data processing and real-time control systems. Secondly, the development of methods, models and tools designed to detect defects in products, both finished and intermediate, as a result of specially organized tests, and the results of operation. These studies, in essence, are based on the implementation of a reactive approach to managing the state of complex systems. At the same time, a much smaller number of studies are focused on managing defects caused by the subjective errors of right holders and developers allowed at different stages of the life cycle of the HSC. In other words, in the defectology of the agroindustrial complex, the methodological, theoretical foundations, methods, models and tools implementing the provisions of a proactive approach to managing the state of complex systems have not been sufficiently developed. 


\section{SERVICE PROFILE}

The literature describes an approach to analyzing the reliability of SS, the conceptual basis of which is the desire to "... look at the reliability of software systems through the eyes of the user" [38]. The object of research is the reliability of the processes of application of software systems (services SS). This approach is fundamentally different from the approaches, the focus of which is the search for defects in software products and the processes of their development at different stages of the SS life cycle. The main idea of the approach aimed at managing the reliability of services is to take into account, at the initial stages of the design, of all the features of the use of substations in order to ensure that the reliability of services meets the requirements of users. The key factors of the features mentioned are:

1) Transfer of accents in the study of the reliability of software from estimating the reliability of a program code (invariant to the conditions of using software) to evaluating the reliability of information services (the system behaves differently in different conditions).

2) The dynamic nature of service reliability assessments: the conditions of use of the system affect the reliability estimate.

3) Subjectivism in assessing reliability: users (subjects, hardware and software systems) using SS in different ways have different ideas about its reliability.

4) Differentiated approach to the selection of reliability criteria, taking into account the different value of different services for users.

The technological basis for the implementation of an approach focused on managing the reliability of services is the construction of profiles. "... A profile is a full set of alternatives (for example, many alternative categories of users, functions, etc.), for each of which there is a certain probability of occurrence ..." [38]. The concept of profiles was first described in [7]. The goals of building an information services profile are:

1) Evaluation of the degree of coverage of business processes information services.

2) Determination of priority directions for the development of a management information support system.

3) Evaluation of the characteristics of stability and uncertainty of the components of the information system as a control object.

The conceptual basis for building information services is taking into account the multidimensionality property of a complex system, which is expressed in the multiplicity of modes of its operation, business processes and business tasks implemented by the management system. The implementation of information service profiles, which are varieties of models of a complex system, depends on the assumptions underlying their construction. The basis for building the profile presented below (Fig. 1) is the following assumptions:

1) Information services are an integral part of the services implemented as part of business processes associated with managing a complex system.

2) The implementation of a business process is the implementation of logically related business tasks.

3) Each business problem can be assigned a set of possible solution schemes, with each of the schemes being an information service.

4) The implementation of a business task is carried out in one workplace. At any one time, only one of the possible schemes for solving a business problem can be implemented in one workplace. In other words, at any given time, only one of the information services associated with a business task can be used.

5) The composition of business problems and their logical connectedness depend on the mode of operation of a complex system.

6) Simultaneous implementation of multiple services at different workplaces is possible, due to the presence of several interacting control loops of a complex system.

7) In different control loops, at the same time it is possible to implement business tasks corresponding to different modes of functioning of the components of a complex system.

8) Subjectivism in evaluating the results of the implementation of business objectives, which is also reflected in the subjectivism of the assessment of consumer properties of business services.

The basis of the study of the properties of the profile of services is the apparatus of mathematical statistics. Each service can be assigned a random value - the time of service failure. The failure of the service is due to the fact that with different sets of source data different sections of codes are activated. Due to the fact that data sets are formed at random times, the service failure time is also a random value.

The rationale for the property of data homogeneity, correlated with service failures, is that the implementation of services is based on solving the same set of applied tasks using data from a predetermined structure, the same target groups of users. Registration of failures is carried out according to the same regulation, defined in the manual for the information and computer system.

The rationale for the reproducibility of data correlated with service failures is that it is possible, if necessary, to repeatedly submit a data set to the service input at which a service failure was registered. As part of the above assumptions, the profile of information services takes the form (Fig. 1). 


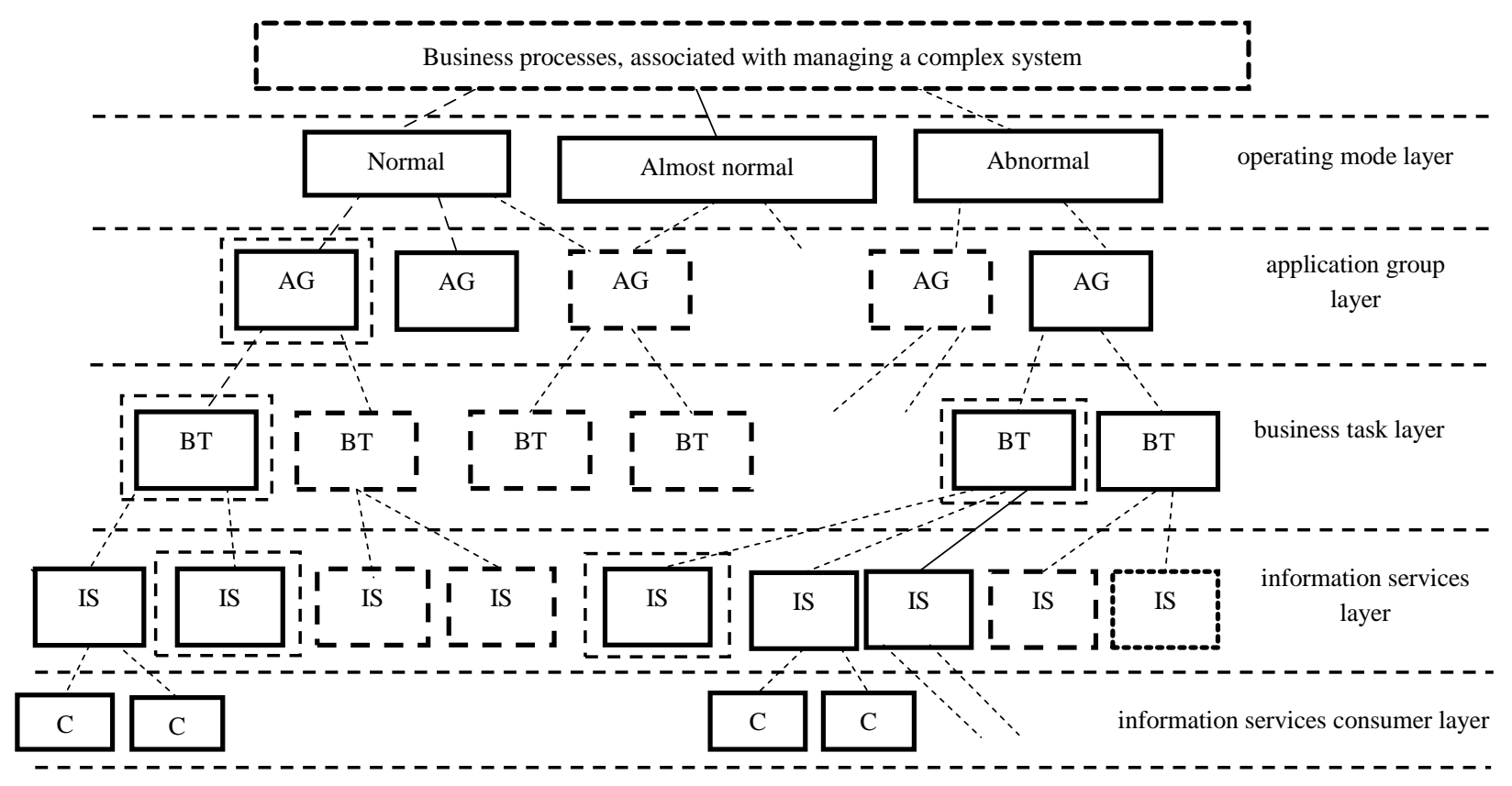

Fig. 1. Information services profile (multiple control loops of a complex system)

In the figure indicated: $\mathrm{AG}$ - applications that together provide the implementation of business processes necessary for the functioning of the system in different modes; BT - business problems solved in the workplace; IS - information services; C information service consumers.

The model presented is a tree in which business processes are the root and consumers $\mathrm{P}$ are leaves. When moving from the root to the leaves, each node of the graph in each layer corresponds to outgoing edges. Each edge is assigned a weight (transition probability), and for each node the normalization condition is true:

$$
\sum_{j} P_{i, j}^{(l)}=1
$$

1 - layer sign; $\mathrm{i}$ - feature node in the layer; $\mathrm{j}$ - sign of edge associated with a node.

Fig. 1 shows in solid lines applications, business tasks and information services corresponding to the current state of "smart factoring"; dashed - those that will be in demand in the future, taking into account changes in consumer preferences; solid and dotted corresponding to both the current and future state of production.

Building a profile of services can be considered as an informational component of the strategy of transferring "smart factoring" from the current state ("as is") to the future ("to be") and allows us to quantify the extent to which business objectives are covered by business services. So, for the i-th task of the business-tasks layer, the degree of coverage is determined:

$$
D C_{i}^{(B T)}=\frac{I S_{i}^{(I)}}{I S_{i}^{(I)}+I S_{i}^{(B I)}}
$$

$I S_{i}^{(I)}-$ the number of information services indicated by solid and dashed lines (implemented services); $I S_{i}^{(B I)}$ - the number of information services indicated by dotted lines (services to be implemented).

Similar estimates can be obtained taking into account the modes of operation of the enterprise. Information services profile is a model of a complex system. Taking into account the multiplicity of approaches to the classification of complex systems within the selected state space, it is possible to propose a different classification of business processes (for example, according to the signs of "basic", "auxiliary", "supporting" processes [8]). Or you can swap the layers of the modes of operation and groups of applications, etc. Or, to base the classification of the functioning modes of symptoms caused by the manifestation of defects of a different nature both in the hardware and software complex and in its environment [40]. From this it follows that "smart factoring" can be associated with a set of profiles that should be considered as complementary.

\section{EVALUATION OF INFORMATION SERVICES RELIABILITY CHARACTERISTICS}

Each simple path from the root of a tree to a leaf can be viewed as an event $E$. Each simple path can be matched with a metric characteristic (implicit profile [38]) $P_{r}$ equal to the product of the weights of the arcs in the simple path. An implicit profile characterizes the probability of an event $E$. Each event $E$ can be associated with an estimate of the reliability Rel, which characterizes the reliability of the information service. In general, the system view model can be assigned to different variants of service profiles:

$$
<E, \operatorname{Pr}, \operatorname{Rel}>
$$


$E$ is the set of possible events; $\operatorname{Pr}$ is the set of probability values (implicit profiles) corresponding to each of the events; Rel is a variety of IS reliability assessments.

A specific feature of evaluating the reliability characteristics of software products in terms of the implementation of non-functional requirements is measuring data [19]. The peculiarities of evaluating the reliability characteristics when evaluating the compliance of the properties of software products with functional requirements are expert evaluations [42].

By postulating a statement about the independence of the reliability characteristics, correlated with functional and non-functional requirements, the resulting reliability assessment of $R_{S}$ can be represented as:

$$
R_{S}=R_{F} * R_{N F}
$$

$R_{F}-$ reliability characteristic correlated to functional requirements; $R_{N F}-$ reliability characteristic correlated to non-functional requirements.

To assess the characteristics of reliability based on subjective assessments of experts, it is proposed to use a well-known approach [37]. With this approach, a set of linguistic scale values is formed, with each k- th value being assigned its own membership function, defined on the axis of the values of the reliability characteristics of the software product. Next, the $r_{k}$ reference values are determined. In terms of the linguistic scale, experts express their opinion on the trait under study, and also indicate confidence in the chosen value, expressed by the number $\mu_{l} \in[0,1]$. The cumulative reliability rating is determined based on the ratio:

$$
R_{F}=\frac{\sum_{l=1}^{n}\left(\mu_{l} * r_{l}\right)}{\sum_{l=1}^{n} \mu_{l}}
$$

$l$ is a sign of an expert; $\mathrm{n}$ is the total number of experts.

As a linguistic analogue of the cumulative assessment of the $R_{F}$ attribute, the value of the linguistic variable is taken, the reference value of which $r_{l}$ is closest to $R_{F}$. The degree of confidence in the selected value of the linguistic variable is determined by the value of the membership function corresponding to a point on the reliability axis. In the described approach, reliability assessment is based on the formation of sets of linguistic variables correlated with the axis of reliability. An example of a linguistic scale with membership functions is shown in Fig. 2

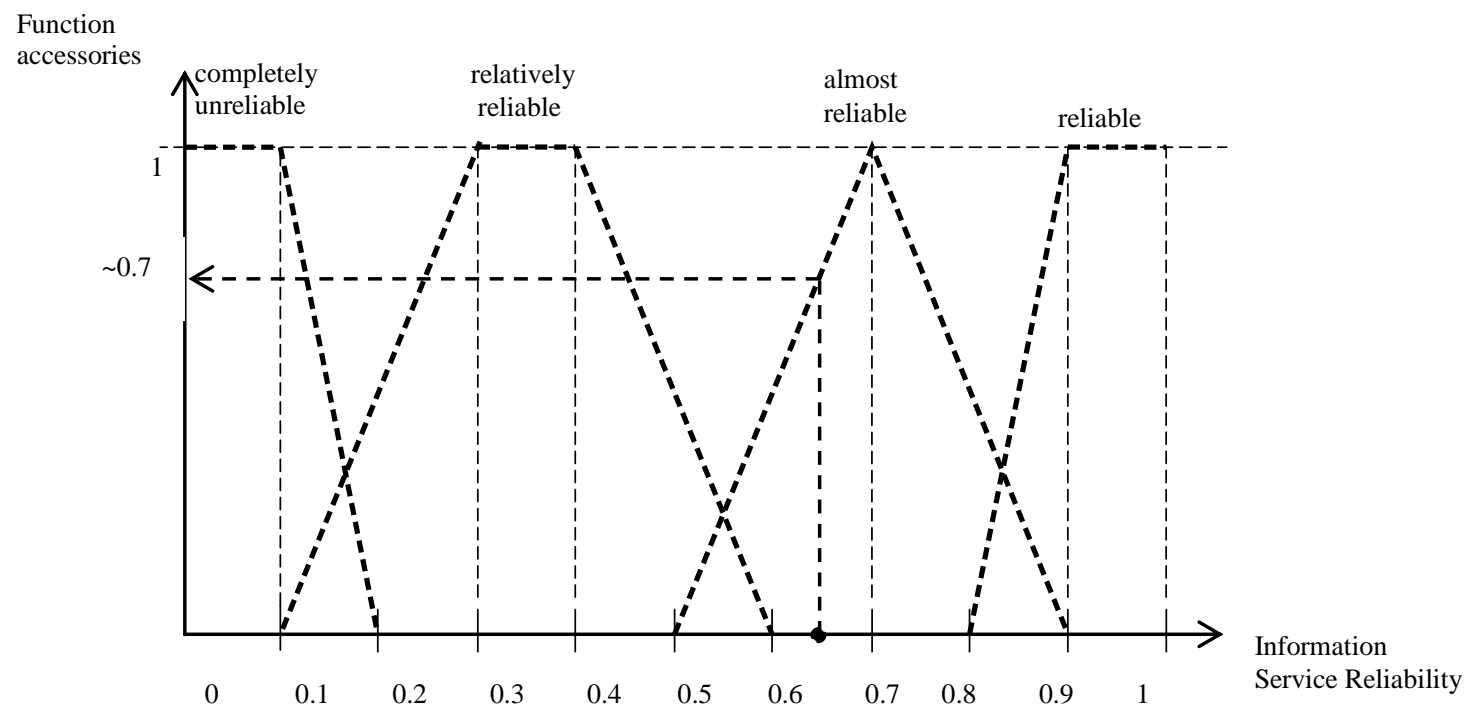

Fig. 2. Linguistic scale membership function

Suppose three independent experts gave the following estimates of the reliability of the i-th information service:

1) Almost reliable (degree of confidence - 0.9).

2) Relatively reliable (degree of confidence $0.3)$.

3) Almost reliable (degree of confidence - 0.6).

The reference value for the linguistic variable is "almost reliable" - 0.7 ; the reference value for the linguistic variable "relatively reliable" is 0.35 (middle of the interval $[0.3 ; 0.4])$. The value of the $R_{F}$ estimate is:

$$
R_{F}=\frac{0.7 * 0.9+0.35 * 0.3+0.7 * 0.6}{0.9+0.3+0.6} \approx 0.64
$$

The reference value closest to the calculated $R_{F}$ value $r_{k}=0.7$ and corresponds to the linguistic variable "almost reliable". The value of the membership function corresponding to $R_{F}=0.64$ is 0.7. Thus, according to the aggregate estimates of the three experts, the i-th information service is "almost reliable", and the degree of confidence in such an 
assessment is 0.7. If it is determined that $\mathrm{R}_{\mathrm{NF}}=0.95$, then the final reliability rating of the service will be $\mathrm{R}_{\mathrm{C}}=0.95 * 0.7=0.665$ with a confidence level of 0.7 .

A feature of the proposed approach to evaluating the reliability characteristics of information services is the ability to compare different information services used to support business processes according to the reliability criterion. In this case, the evaluation of reliability characteristics is carried out on the basis of a comparison of the conformity of service properties to functional and non-functional requirements for software products.

The limitations of the approach are:

1) The subjectivity of experts in the formation of a set of linguistic variables,

2) Subjectivism in assessing the compliance of information service properties with user expectations. "Man's satisfaction is a purely subjective factor ... This factor eludes a rational, logical definition ..." [34]

3) Subjectivism in the choice of membership function.

A possible approach to resolving the identified constraints is to use the provisions of the theory of convergent control [34].

\section{ACKNOWLEDGMENT}

This work was supported by grant RFBR 19-0800177 «Methodological, theoretical and model bases for the management of functional safety of hardware and software systems as part of distributed complex technical systems».

\section{REFERENCES}

[1] Schwab, K. Chetvertaya promyshlennaya revolutsiya [The Fourth Industrial Revolution]. - M: publishing house «E», 2017. - 208 p. (In Russian).

[2] Yaninsky, O.N. Razmyshleniya nad knogoy: Klaus Schwab. Chetvertaya promyshlennaya revolutsiya [Reflections on the book: Klaus Schwab. The Fourth Industrial Revolution]: M.: publishing house «E», 2018. - 7 p. (In Russian).

[3] Lorenz Granrath. Japan's Society 5.0: Going Beyond Industry 4.0. https://www.japanindustrynews.com/2017/08/japanssociety-5-0-going-beyond-industry-4-0/ (accessed 20.02.2019).

[4] Nancy G. Leveson, Clark S. Turner. An investigation of the Therac-25 accidents. IEEE Computer, 26(7):18-41, July 1993.

[5] Jessica MacNeil. Mariner 1 destroyed due to code error, July 22 , 1962

2018 https://www.edn.com/electronics-blogs/ednmoments/4418667/Mariner-1-destroyed-due-to-code-error-July-22--1962 (accessed 18.02.2019).

[6] Timofeev A. Adaptivnoe upravlenie I intellektualnyy analiz infornatsionnyh potokov v komp'yuternyh setyakh [Adaptive management and intelligent analysis of information flows in computer networks]. - St. Petersburg.: «Anatoliya», 2012. 280 p. (In Russian).

[7] Cheung R. A User-oriented Software Reliability Model // IEEE Trans. Soft. Eng. - 1980. - SE-6, N 2. - pp. 11 - 125.

[8] Project Management Institute, Guide to the Body of Knowledge on Project Management (PMBOK). - M: OlympBusiness, 2018. -588 p.
[9] Timofeev A. Pochemy padayut IT-proekty [Why IT-projects fail?] // Systems design practice. Scientific and educational journal, 2017. p.2-12. (In Russian).

[10] Standish Group 2015 Chaos Report - Q\&A with Jennifer Lynch. https://www.infoq.com/articles/standish-chaos-2015. (accessed 10.02.2019).

[11] IEEE Std 830-1993. Recommendations for Developing Software Requirements Specifications.

[12] Haapanen Pentti, Helminen Atte. Failure Mode and Effects Analysis of Software-Based Automation Systems // STUKYTO-TR 190, August 2002. - 36 p.

[13] Hatem A. Khater, A. Baith Mohamed, and Sara M. Kamel. A Proposed Technique for Software Development Risks Identification by using FTA Model // World Academy of Science, Engineering and Technology International Journal of Computer and Information Engineering. Vol. 7, No. 1, 2013. - pp.105-111.

[14] Vittih V. Neodnorodnyy aktor i povsednevnost' kak klyuchevoe ponyatie evergetiki [Heterogeneous actor and everyday life as a key concept of evergetics]: preprint. Samara: Federal State Budgetary Institution of Science ICSM RAS, 2014. - 12 p. (In Russian).

[15] Loshkareva E., Luksha P., Ninenko I., Smagin I., Sudakov D. Naviky budushchego. Chto nuzhno znat' I umet' v sovremennom mire [Skills of the future. What you need to know and be able to in the new complex world[ // World Skills, Global Education Future, Future Skills. - 92 p. (In Russian).

[16] Haken G. Secrets of nature. Synergetics: the study of interaction. Moscow-Izhevsk: Institute for Computer Studies, 2003. $-320 \mathrm{p}$.

[17] Ritu Soni, Ashpinder Preet. Cognitive Approach to Root Cause Analysis for Improving Quality of life: A case study for IT Industry // International journal of informative and futuristic research (Online). Vol. 1 Issue 1, August September 2013. -8 p.

[18] Jayson P. Vucovich, Robert B. Stone, Xiaoqing Frank Liu, Irem Y. Tumer: Risk Assessment in Early Software Design Based on the Software Function-Failure Design Method. // 31st Annual International Conference COMPSAC (1) 2007: pp. 405-412

[19] Lipaev V. Funktsional'naya bezopastost' programmnykh sredstv [Functional security software]. M.: SINTEG, 2004. 348 p. (In Russian).

[20] Bykovsky S., Gorbachev Y.G., Kluchev A., Pensky A., Platynov A. Sopryazhennoe proektirovanie vstraivaemykh sistem [Hardware/Software Co-Design] - St. Petersburg.: IFMO, 2016. - 105 p. (In Russian).

[21] Platunov A., Postnikov N. Visokourovnevoe proektirovanie vstraivaemykh sistem [High-Level Embedded Design]. - St. Petersburg.: IFMO, 2011. - 121 p. (In Russian).

[22] Edward A. Lee. Cyber Physical Systems: Design Challenges. Technical Report No. UCB/EECS-2008-8 http://www.eecs.berkeley.edu/Pubs/TechRpts/2008/EECS2008-8.html (accessed 20.02.2019).

[23] Paul Grünbacher, Anna Perini (Eds.) Requirements Engineering: Foundation for Software Quality // 23rd International Working Conference, REFSQ 2017, Essen, Germany, February 27 - March 2, 2017, Proceedings.

[24] Wenhua Hu, Jeffrey C. Carver, Vaibhav K. Anu, Gursimran S. Walia, Gary L. Bradshaw. Detection of Requirement Errors and Faults via a Human Error Taxonomy: A Feasibility Study // National Science Foundation Awards 1421006 and 1423279.

[25] Bill Davey, Kevin R. Parker. Requirements Elicitation Problems: A Literature Analysis // Issues in Informing Science and Information Technology, Vol. 12, 2015, 82 p.

[26] Tomomi Kataoka, Ken FURUTO, Tatsuji Matsumoto. The Analyzing Method of Root Causes for Software Problems // SEI TECHNICAL REVIEW, NUMBER 73, OCTOBER 2011. -5 p. 
[27] Roland J. Duphily. Root Cause Investigation Best Practices Guide // AEROSPACE REPORT NO. TOR-2014-02202, May 30, 2014 - $95 \mathrm{p}$.

[28] Stan Kaplan, S. Visnepolschi, B. Zlotin, A. Zusman. New Tools for Failure and Risk Analysis / Anticipatory Failure Determination (AFD and the Theory of scenario Structuring. Ideation Intl Inc, October 8, 1999. - 86 p.

[29] D. Nassar, W. AbdelMoez, M. Shereshevsky, H. H. Ammar, Ali Mili, Bo Yu, S. Bogazzi. Error Propagation Analysis of Software Architecture Specifications // Proceedings of the International Conference on Computer and Communication Engineering (ICCCE'06), Vol.1, Kuala Lumpur, Malaysia, May 9-11, 2006. pp. 496-501.

[30] Lee P.A., Anderson T. Fault tolerance, principles and practice. Vol.3. Springer Science \& Business Media, 2012. $320 \mathrm{p}$.

[31] I. Verzola, A.E. Lagny, and J. Biswas, "A Predictive Approach

Failure Estimation and Identification for Space Systems Operations," in Proc. 13th international conference on space operations,

California, USA, May 2014.

[32] V. Cortellessa and V. Grassi. "A Modeling Approach to Analyze the Impact of Error Propagation on Reliability of Component-Based Systems"// Proceedings of the 10th International Symposium on Component-Based Software Engineering, CBSE 2007 (Berlin, Heidelberg), SpringerVerlag, pp. 140-156.

[33] Zhu Y.-M. Failure-Modes-Based Software Reading. Chapter 2: Software Failure Mode and Effects Analysis, 2017, XI, pp.7-15.

[34] Raikov A. Konvergentnoe uprablenie i podderzhka resheniy [Convergent management and decision support]. - M.: IKAR, 2009. - 243 p. (In Russian).

[35] Raikov A. Setevaya expertnaya podderzhka reshenyy [Network expert decision support] // Large system management. 2010. pp. 758-773. (In Russian).

[36] Vittih B. Vvedenie $\mathrm{v}$ teoriuy intersub"ektivnogo upravleniya [Introduction to intersubjective control theory] / Samara: RAS, 2013. - 64 p. (In Russian).
[37] Pelaez C.E, Bowles J.B. Using fuzzy cognitive maps as a system model for failure modes and effects analysis. Information Sciences, 1996; 88(1), pp. 177-199.

[38] Moroz G., Koval G., Korotyn T. Konstepstiya profiley v inzhenerii nadezhnosti programmnykh sistem [The concept of profiles in the reliability engineering of software systems] // Mathematical Machines and Systems. - 2004. - №1. - pp. 166 - 182. (In Russian).

[39] Novikov D. Kibernetika 2.0 [Cybernetics 2.0] // «Management problems». - M.: «SenSiDat-Control», 2016, pp. 73- 81. (In Russian).

[40] Long Wang, Akhil Sahai, James Pruyne. A model-based simulation approach to error analysis of IT Services // Enterprise Systems and Software Laboratory, HP Laboratories Palo Alto, HPL - 2006-181, December 5, 2006.

[41] Druzhinin G. Nadezhnost' avtomatizirovannykh sistem [Reliability of automated systems]. - M.: "Energy". 1977. 536 p. (In Russian).

[42] Kano N., Seraku N., Takashi F., Tsuji S. Attractive Quality and Must-be Quality. The Journal of the Japanese Society for Quality Control, 1984, 14(2), pp. 147-156.

[43] Fazel Ansari, Marjan Khobrehc, Ulrich Seidenbergd, Wilfried Sihnab. A problem-solving ontology for human-centered cyber physical production systems. CIRP Journal of Manufacturing Science and Technology. Volume 22, August 2018, pp. 91-106.

[44] Carsten Wittenberg. Human-CPS Interaction - requirements and human-machine interaction methods for the Industry 4.0. IFAC-PapersOnLine. Volume 49, Issue 19, 2016, pp. 420425.

[45] M.Mulder, D.M.Pool, D.A.Abbink, E.R.Boer, M.M.van Paassen. Fundamental Issues in Manual Control Cybernetics. IFAC-PapersOnLine. Volume 49, Issue 19, 2016, pp. 1-6.

[46] H.Ahuett-Garzaa, T.Kurfessb. A brief discussion on the trends of habilitating technologies for Industry 4.0 and Smart manufacturing. Manufacturing Letters. Volume 15, Part B, January 2018, pp. 60-63.

[47] Andrea Benešová, Jiří Tupa. Requirements for Education and Qualification of People in Industry 4.0. Procedia Manufacturing. Volume 11, 2017, pp. 2195-2202. 